\title{
Augmented Reality Interactive Learning Model, using the Imagineering Process for the SMART Classroom
}

\author{
Panita Wannapiroon ${ }^{1}$, Prachyanun Nilsook ${ }^{1}$, Nutthapat Kaewrattanapat ${ }^{2}$, \\ Naphong Wannapiroon ${ }^{3}$, Wera Supa ${ }^{4}$ \\ ${ }^{1}$ King Mongkut's University of Technology North Bangkok,Bangkok, Thailand \\ ${ }^{2}$ Suan Sunandha Rajabhat University,Bangkok, Thailand \\ ${ }^{3}$ Rajamangala University of Technology Suvarnabhumi, Phranakhon Si Ayutthaya, Thailand \\ ${ }^{4}$ Rajamangala University of Technology Tawan-ok,Bangkok, Thailand
}

\begin{abstract}
The objective of this research is to create an augmented reality interactive learning model, using the Imagineering process for the SMART classroom. The overall method is divided into 4 stages: (1) development of the augmented reality interactive learning model; (2) development of using augmented reality learning materials; (3) development of best practices teachers of ICT; and (4) expanding these results with the augmented reality interactive learning model. The target group for the research is $\mathbf{3 0}$ excellent tertiary teachers, 20 vocational instructors, 600 vocational students and 900 tertiary students. Qualified experts certified that the interactive learning model developed is at the most appropriate level. The interactive learning material activities consist of four main processes: preparation, prototype teacher development, outreach, and evaluation. The results of evaluation indicate that the quality of creative innovation is at the highest level.
\end{abstract}

Keywords - Augmented Reality, Interactive Learning, Interactive Media, Imagineering, SMART Classroom

DOI: 10.18421/TEM103-51

https://doi.org/10.18421/TEM103-51

Corresponding author: Naphong Wannapiroon, Rajamangala University of Technology Suvarnabhumi. Email: naphong.w@rmutsb.ac.th

Received: 20 January 2021.

Revised: 04 August 2021.

Accepted: 10 August 2021.

Published: 27 August 2021.

(c))BY-NC-ND (C) 2021 Panita Wannapiroon et al; published by UIKTEN. This work is licensed under the Creative Commons Attribution-NonCommercial-NoDerivs 4.0 License.

The article is published with Open Access at www.temjournal.com

\section{Introduction}

In Thailand, education is emphasized as the key strategy for national development. The Office of the Education Council, Ministry of Education, established the national education plan 2017 - 2036 [1] to determine the goals and directions of education management within the country. The aims of the plan are to: 1) provide education for all Thai people so that all have equal opportunities to access quality education; 2) develop an effective educational management system; 3) develop manpower to work in accordance with the needs of the job market and national development; 4) establish the vision that enables Thai people to learn throughout their life to a high standard; 5) determine a strategy to enable all new teachers to develop information technology skills so that learners can access information; and 6) develop a high-speed fibre-optic network system and wireless access for all schools and communities. The teachers with best practices are important in ensuring that learning is of high quality [2]. In the era of digital citizens, the most distinctive component is ICT management as a key factor in developing an innovative education [3]; the instructor must become a learning designer and facilitate learning, allowing learners to learn by doing so that it comes from within their own mind and brain.

Teachers and learners in all sectors of education continue to have access to a growing number of mobile Augmented Reality (AR) applications. AR has seen a significant increase in applications in a number of fields in recent years. One of the areas - in which the AR has been applied to - is education [4]. AR technology is a digital media form of Virtual Reality (VR) technology that utilizes virtual systems combined with visual technology to create virtual worlds for users. AR technology is applied in many different fields, especially education technology. AR has been used to develop teaching materials from kindergarten to university levels [5]. 
The SMART Classroom is an appropriate learning environment [6] that includes the following dimensions: 1) S: Showing is the ability to present information in teaching and learning through technological media, which is cognitive characteristic; lectures given through smart classroom significantly increase the academic achievements of the students. 2) M: Manageable refers to the competent management of media, equipment, teaching system, resources, and the environment of the SMART classroom; 3) A: Accessible denotes the ability to access learning resources using SMART classrooms through a variety of media; 4) R: Real-time Interactive refers to learning experiences created and taught by teachers through interactive computer technology media in SMART classrooms. It is clear that basic aspects of a classroom are of importance in helping lecturers to make classes more flexible or adaptable [7]. 5) T: Testing is concerned with the qualitative examination of learning activities or checking learning behaviour using the SMART classroom.

The arrangement of learning activities, according to the Augmented Reality, Interactive Learning, Interactive Media, Imagineering, SMART Classroom model, consists of the following steps: 1) imagination, 2) designing, 3) development, 4) improvement, 5) presentation, and 6) evaluation, concepts adapted from Walt Disney's Imagineering model [8]. Therefore, the researcher investigates and generates an interactive learning media development model with augmented reality, using the Imagineering process for a SMART classroom that has revolutionized Thai education in the digital age.

\section{Research Objectives}

1. To develop the augmented reality interactive learning model, using the Imagineering process for the SMART classroom.

2. To develop learning materials, using the augmented reality interactive learning model.

3. To develop the Ministry of Education's best practice teachers of information and communication technology in the production of such learning materials.

4. To expand the production of learning materials, using the augmented reality interactive learning model.

\section{Theoretical Foundation}

\subsection{Imagineering}

"Imagineering" is a portmanteau of the words "Imagine and Engineer". Imagineering means adding imaginative elements into something that is practical; creating images in the mind. It is a tangible form of invention and innovation. The Imagineering process has 6 aspects and 17 steps consisting of: [9]

1) Imagine: the process of determining the imagination of the work (problem), the brainstorming process regarding how the imagination works (brainstorm), the process of expressing opinions (discussion), and the process of analysing the feasibility of the imagination (feasibility).

2) Design: the process of drafting (draft), the process of writing a story board, the process of writing the script, and the process of creating a model prototype.

3) Development: the process of creating (create) and the process of testing (test).

4) Presentation: the process of showing the work (show), the process of the contest (contest), and the process of listening to opinions (suggestion).

5) Improvement: the process of revising the work (revised) and the process of concluding the work (conclusion).

6) Evaluation: the process of evaluating the imagination (process evaluation) and the process of evaluating the quality of work (product evaluation).

The learning process of Imagineering, therefore constitutes a way to develop learners in the $21^{\text {st }}$ century that focus on self-learning, creativity, and innovation. [10]

\subsection{SMART Classroom}

The SMART classroom as a new frontier for the university, provides a suitable learning environment that includes locations, tables, chairs, electrical systems, audio, and air conditioning systems, mobile and wearable devices, tracking technologies, data collection systems, big data processing capabilities, etc. [11]. It facilitates various learning activities in the classroom, whether this is a small group activity, a lecture, project work, or a presentation in front of the class. These enable learners to develop the skills to use technology for learning (learning skill) and the skills of searching by themselves (research skill). This enables them to meet their individual learning needs and participate in the collaborative learning of learners and teachers to their full potential. Moreover, the use of smart classroom also helps in the process of teaching and learning in the classroom where learning becomes more effective and flexible [12].

A SMART classroom for the education can be defined as the exploitation of a smart environment in a learning process [13]. SMART classroom is a unique learning resource, different from a 
conventional classroom, that enhances teaching and learning experiences, training, and skills training in various fields. It focuses on facilitating collaborative learning across multiple technologies and audiovisual media, creating both regular and out-of-class learning systems to support effective distance learning [14].

\subsection{Augmented Reality}

Virtual and augmented reality technology is becoming more commonly available within educational environments [15]. Augmented Reality (AR) is a type of digital media that combines the use of Virtual Reality (VR) with visual technology for the user. AR is used in many fields, especially in education. It is a notable technology for pedagogical use. AR differs from VR. It has been developed into teaching and learning materials from kindergarten to university levels; specific insight for exploring immersive learning approaches utilizing virtual and augmented reality tools and applications in a variety of disciplines is needed and also concerns regarding accountability for ethical design and the use of VR/AR products in virtual learning environments [16].

AR is a new technology that combines the real world with the virtual world through a hardware device combined with the use of different software. This makes it possible to see images that look like objects and that are displayed on the screen, where they are transformed into a 3D object floating above the real surface. This creates a visual effect that shows the object moving and creates a sense of excitement. Both AR and VR as elements of the mixed reality continuum rely on the humancomputer interaction [17].

$\mathrm{AR}$ has a working principle that can be categorized into 2 types of image analysis: using marker as the main work (marker-based AR), and using different characteristics in the image for analysis (marker-less based AR) [18]. The elements of virtual reality technology include a Marker (also known as a markup), video camera, webcam, cell phone camera, or other sensors. Display components include a display device and processor software for a 3D object.

\subsection{Interactive Learning}

Interactive learning is an approach to teaching and learning that focuses on various ways in which learning activities can "interact" with learners. One of the key components of interactive learning is "information" and the design of teaching materials to attract learners, creating a greater desire to learn. Students can prepare for class by interacting with provided resources to reduce lecture time and allow more engagement in class [19]. Through interactive learning, learners engage with various media such as computers, smartphones, tablets, and social networks. Such engagement helps create a comfortable level of interaction between learners and teachers. Nowadays, this form of learning thrives on digital technology that has evolved enormously. One of the approaches widely employed to study interactive learning is "mobile learning" [20], smartphone use boosted learners' critical thinking, creative thinking, communication and collaboration skills. In addition, those students who performed interactive learning are more likely to pass the course with distinction than those who did not show this attribute [21]. Because social and interactive engagement is integral to cognitive development, the learning spaces that are most conducive to interactive learning should be investigated. This is an area that motivates learners, especially children and young people, who are close to the new generation of electronic devices.

\section{Research Methodology}

To meet the research objectives, the research was conducted in 4 phases as follows:

Phase 1: Development of the augmented reality interactive learning model, using the Imagineering process for the SMART classroom.

1.1. Research on the status of teaching and learning management, problems, and needs in the use of information and communication technology for education among teachers, students, and school administrators.

1.2. A synthesis of literature related to the augmented reality interactive learning model.

1.3. Development of the augmented reality interactive learning model, using the Imagineering process for the SMART classroom, presented on an illustrated essay sheet.

To certify the suitability of the interactive learning model, it was criticized and assessed by 15 experts. The tool used to collect the data was an evaluation form to certify the suitability of the learning style, which was assessed at five levels: most appropriate, most, moderate, least, and least appropriate. The data was analysed, using arithmetic means and standard deviations.

Phase 2: Development of the Ministry of Education's best practice teachers of information and communication technology in the production of learning materials.

2.1. Development of teachers with excellent practice: A group of teachers with excellent practice at the tertiary level, 30 people and 20 vocational educations, a total of 50 people, implementing 
the technology model for human performance technology, organized a 5-day workshop for prototype teachers with excellent practice in producing the augmented reality interactive learning materials using the Imagineering process.

2.2. Development of the augmented reality interactive learning materials, using the Imagineering process.

- 50 teachers with excellent practice created 50 augmented reality interactive learning materials. The creation of learning materials followed the 6-step process of Imagineering: Imagination, Design, Development, Presentation, Improvement, and Evaluation. These were integrated with the 5 steps of Instructional Design, Analysis, Design, Development, Implementation, and Evaluation.

- Teachers created a learning management plan using the augmented reality interactive learning materials they had developed.

- Presentation and review of the augmented reality interactive learning materials by 3 experts on the content and technical aspects of augmented reality.

- Assessment of the quality of the augmented reality interactive learning materials by the same 3 experts. The tool employed in the evaluation was: The media quality assessment form for content and technical Augmented Reality. The quality of the assessment was rated on a five -level scale: Excellent, Good, Fair, Poor, and Bad. The data were analysed using arithmetic means and standard deviations.

Phase 3: Expanding the results of the production of learning materials using the augmented reality interactive learning model.

50 teachers with excellent practice expanded the results by implementing the Imagineering Process to 900 tertiary students and 600 vocational students from 5 regions in Thailand, including North, Central, South, East, and Northeast of Thailand, an overall total of 1,500 people. The process was as follows:

3.1. Teachers with excellent practices set content boundaries and design activities to enable students to create interactive learning materials by independently creating their own materials, based on their imagination and creativity.

3.2. Teachers with excellent practices performed a 6step learning activity based on the Imagineering Process as follows:
1) Imagination phase: The instructor asks the student what they want to create from their own imagination and to determine the topic they want to make work in reality.

2) Design: The instructor allows students to draft whatever they want to create in the form of scripts and storyboards, stimulating their imaginations with a focus on creativity.

3) Development: Learners use draft drawings, scripted stories, and storyboards to create the interactive learning materials based on their imagination.

4) Presentation: Learners present the interactive learning materials they have created in front of the class.

5) Improvement: The instructor organizes the production of critical comments on the development of learning materials to reflect people's ideas and to allow them to participate in exchanging learning, suggestions, and improvements.

6) Evaluation: Teachers and learners jointly evaluate the results of the media created through the process of imagination and assess the quality of the interactive learning materials learners created.

3.3. Higher education and vocational students create interactive learning materials based on the Imagineering process.

3.4. Teachers assess the quality of students' creativity and innovation using Imagineering learning. The tools used in the assessment were the creativity assessment and creative innovation quality assessment using rubric assessment criteria. The criteria for assessment were at 5 levels: Excellent, Good, Fair, Poor, and Bad. The data were analysed using arithmetic means and standard deviations.

Phase 4: Development of the augmented reality interactive learning materials using the Imagineering process for the SMART classroom.

4.1. Research on the teaching and learning conditions, problems, and needs regarding the use of interactive learning materials with augmented reality by teachers, students, and education providers.

4.2. A synthesis of literature related to the development of interactive learning materials based on augmented reality using the Imagineering process for the SMART Classroom.

4.3. The development of a model for these interactive learning materials.

4.4. Criticism of the model by 10 experts.

4.5. Evaluation by 15 experts to certify the development of the interactive learning 
materials. The tool used to collect the data was an assessment form that certified the suitability of the learning model. There were five levels of assessment: Excellent, Good, Fair, Poor, and Bad. The data were analysed using arithmetic means and standard deviations.

\section{Research Findings}

\section{Part 1: The Augmented Reality interactive learning model using the Imagineering Process for the SMART classroom.}

1.1. There are 6 main components of the augmented reality interactive learning model: teacher, student, SMART classroom environment, augmented reality learning resources, and content.

\section{1) Teacher}

- The teacher motivates and inspires students to learn, poses challenging questions, and organizes a variety of teaching activities to enable students to find answers on their own. Teachers are knowledgeable people who will guide students to think, challenge them through project-based problem-solving processes, and monitor their progress in creating a product, workpiece, or portfolio, The teacher encourages students to discuss, appreciate, and summarize the correct directions to take after the activity.

\section{2) Students}

- Students competently participate in a systematic learning process by conducting research or creating workpieces, expressing opinions, and presenting and sharing what they have learned, their knowledge, and their expertise. They have the ability to work in groups, engage in collaborative learning, allocate functions and roles to various group members, and can search for resources to solve real-world problems relating to everyday contexts, questions, issues, and challenges. They possess self-learning skills, can search for knowledge from various learning sources, are able to create workpieces to enhance their learning of the subject matter, can be selfsufficient in assessing their learning, exhibit open-mindedness, listen to the reasons given by the group, and are outside educators.

3) SMART classroom learning environment: The characteristic features of the SMART classroom learning environment are as follows.

- Encourages students to work together as a group; such grouping must be organized carefully so that students can learn together happily and with success.
- Creates a flexible learning environment, in which students learn and work independently. Students have time to learn and work both in the classroom and outside the classroom, possibly using social media.

- Creates opportunities to communicate, present, and share new ideas in their own words. The knowledge students discover is provided to other group members and disseminated to other groups of students or interested parties with expert advice to ensure the fulfilment of student learning.

- Encourages students to reflect on what they have learned and express their opinions rationally without using emotions or personal feelings.

- Allows students to take action in the form of project work, product creation, or innovation.

The SMART classroom learning environment has 5 dimensions, each of which is detailed as follows.

- S: Showing: The ability to present information in teaching and learning through teaching technology materials, a feature known as Cognitive Characteristic.

- M: Manageable: A managerial capacity that includes media management, management of materials, and organization of the teaching system, as well as resources and the SMART classroom environment.

- A: Accessible: Accessibility to learning resources within the SMART classroom through various media.

- R: Real-time Interactive: The interactive creation of teaching experiences by teachers, including media-based interactive computer technology learning in a SMART classroom.

- T: Testing: This comprises a qualitative examination of learning activities, or the examination of learning behaviour within SMART classrooms, as shown in Figure 1.

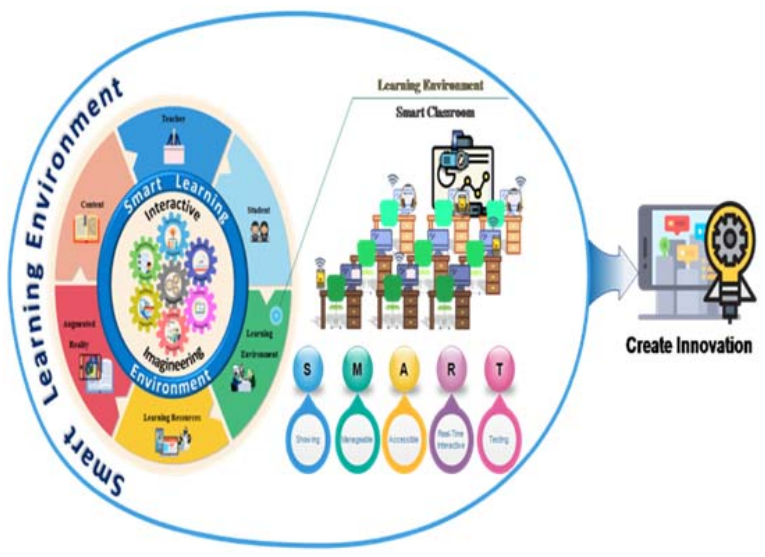

Figure 1. SMART classroom learning environment for the augmented reality interactive learning model by using the Imagineering process 
4) Learning resources: The characteristic features of the learning resources employed in the composition of the augmented reality interactive learning model are as follows:

- A versatile learning resource to suit the individual needs of each student, both as a documented source of knowledge, Internet, and professionals in the fields of interest to students.

- Learning resources that students can easily access.

- Sufficient numbers and types of basic materials necessary for learning to support students and the testing of work pieces.

- A system to promote the use of augmented reality such as available internet networks, and sufficient equipment to access this.

- A learning resource that students can apply in the creation of augmented reality work.

- Easily accessible content.

5) Augmented Reality: The characteristic features of augmented reality in the composition of the augmented reality interactive learning model are as follows:

- Flexible, can be used with a wide range of tools, and teachers can apply and adapt teaching and learning in a variety of methods and contexts. Students can use them for learning anywhere and at any time.

- Interacting, and an ability to interact with users, denotes the relationship between the real environment and the virtual environment.

- Improving learning efficiency, helping students to understand contents so that they spend less time learning, reducing the cognitive burden resulting in effective learning, helping to make abstract content appear more tangible.

- Convenient for learning without the need for large experimental tools or multiple materials, thus reducing equipment purchase costs. Students can use it for self-learning with a variety of devices.

- Motivating learning, promoting independent learning in a multimedia format. This gives students the opportunity to learn at their own pace according to their needs; it allows students to experience abstraction and become concrete. It stimulates their interest and they develop a positive attitude to study.

- Promotes collaborative learning, facilitates collaboration among student groups, and among students and teachers, enables students to interact well between groups, promotes the creation of augmented reality work in a variety of contexts.
6) Content: The characteristic features of the content in the composition of the augmented reality interactive learning model are as follows.

- Encourages students to engage in creative thinking processes to develop projects, invent, or create an innovation that leads to its practical use in their daily lives.

- Challenges students to acquire additional knowledge that forms the basis of invention, innovation, or work that can be used in real life.

- Develops an ability to integrate the content or the skills of various subjects in an interdisciplinary way to achieve complete learning.

- Subjects that lead to experiences that can be applied in the real lives of the students.

- Consistent with the core curriculum structure of basic education to provide students with knowledge and an understanding of the subject matter according to the standards of the basic education core curriculum.

- Suitable for students' abilities, interests, and age, but challenges them to seek new knowledge.

The Augmented Reality Interactive learning activity using the Imagineering Process for the SMART classroom consists of 2 steps:

\section{1) Pre-teaching preparation process:}

- Orientation clarifies learning objectives and methods of teaching and learning.

- Practice using tools for interactive learning.

- Assessment of creativity before studying.

2) The Interactive Imagineering process comprises the following 6 steps:

- Imagining motivation: This is the process of defining the imagination of the works (problem), the process of brainstorming to imagine the work (brainstorm), discussion, and the process of analying the possibility of imagination (feasibility) to help motivate students, generate curiosity, and give rise to inspiration.

- Designing cooperation: This is the process of drawing (draft), writing storyboards (storyboard), scripting (script), and modelling (prototype) which contributes to learning, resulting in collaboration between student groups and between students and teachers.

- Developing practice: This is the creating process (create) and functional testing process (test). It is a practice that involves creating innovation using learning materials from technology. It is a form of learning management that allows students to take action in the form of project work, creation workpieces, or innovation. 
- Presenting creation: This is the process of displaying works (show), competing (contest), and receiving opinions (suggestion). It encourages creativity and participation.

- Improving feedback: This is the process of editing the results (revised) and summarizing the work (conclusion). It involves primary improvement of the output of the presentation, encouraging students to reflect on what they have learned and to express their opinions logically.

- Evaluating authentication: This is the process of evaluating the imagination (process evaluation) and of assessing the quality of work (product evaluation) according to the reality of the workpiece. It enables learners to assess their understanding of the learning process. Assessment is undertaken by both peers and participatory teachers.
The Interactive Imagineering Process, as shown in Figure 2.

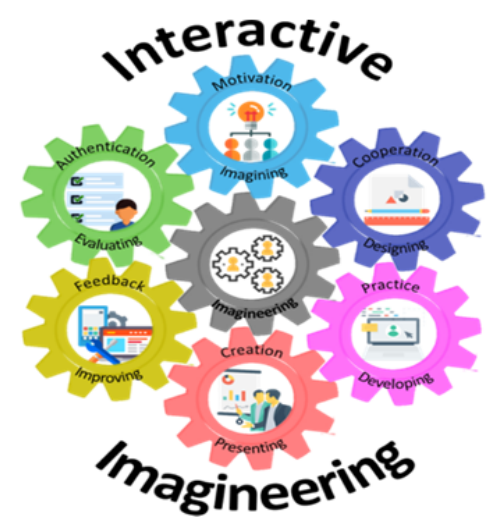

Figure 2. The Interactive Imagineering Process

1.2) The augmented reality Interactive learning model using the Imagineering process for the SMART classroom is depicted in Figure 3.

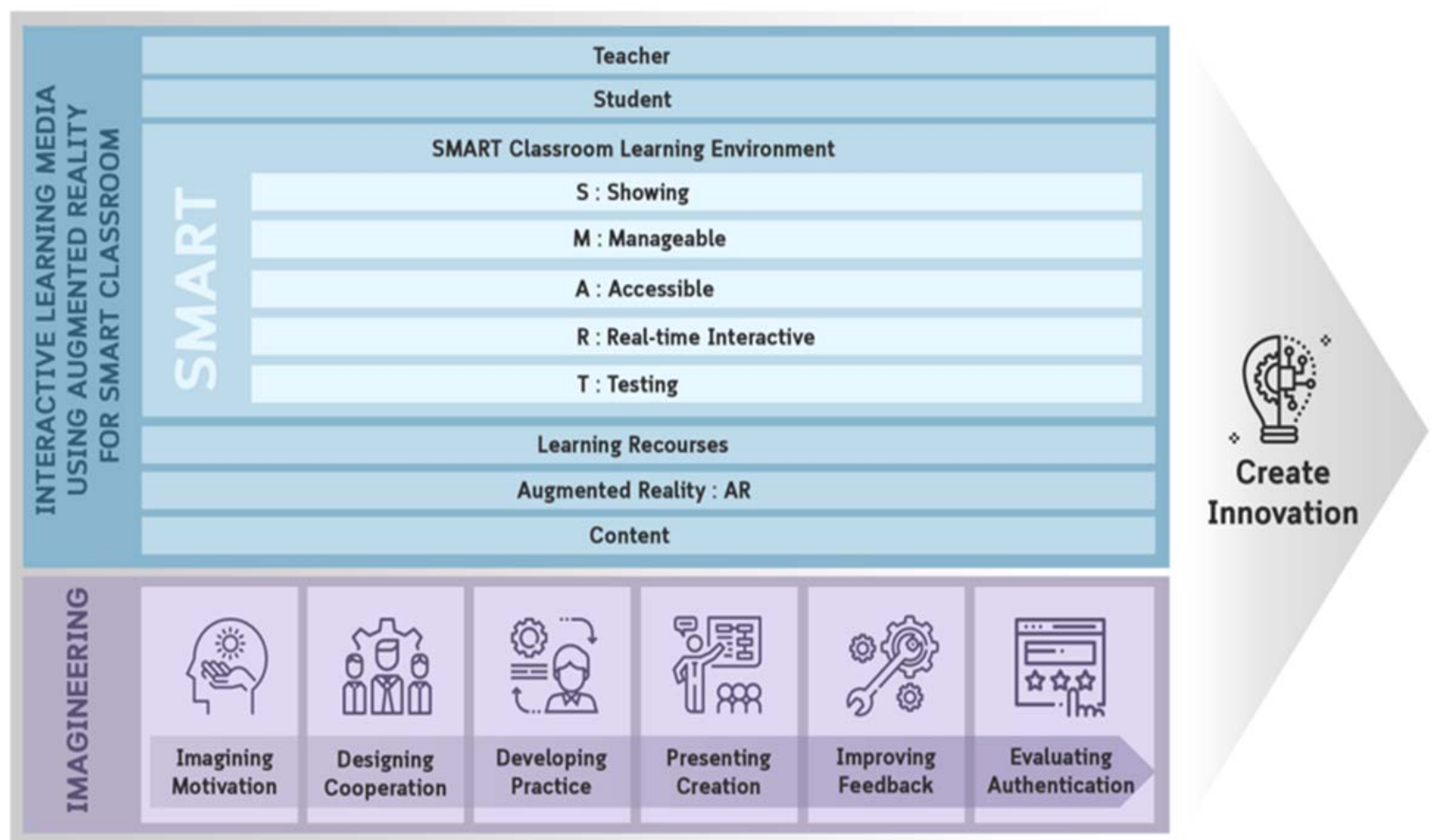

Figure 3. The augmented reality interactive learning model using the Imagineering process for the SMART classroom

1.3) Evaluation results for the development of the augmented reality interactive learning model. The 15 experts found the development of learning materials to be at the highest level.
Part 2: interactive learning media development model with augmented reality using the Imagineering process for the SMART classroom

2.1) Elements of the interactive learning media development model

The results show that the model comprising 5 factors: peopleware, software, hardware, procedure, and data and information, as presented in Figure 4. 


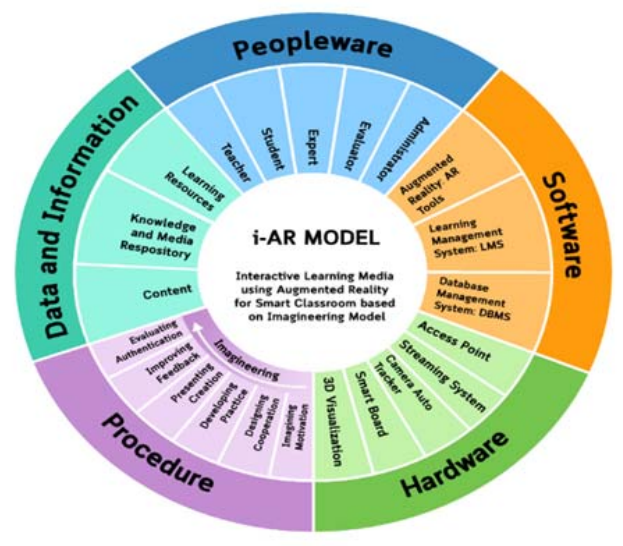

Figure 4. The interactive learning media development model with augmented reality using the Imagineering process for the SMART classroom

As presented in Figure 4., the model can be explained as follows.

\subsection{1) Peopleware}

2.1.1.1) The characteristics of the instructor or teacher.

- Motivates and inspires students to learn, poses challenging questions, and sets a variety of teaching and learning activities so that students can learn to find answers on their own.

- Is a facilitator and counsellor who stimulates and encourages students to learn fully to fulfil their own potential.

- Provides counselling to students and encourages them to progress in learning.

- Is knowledgeable and guides students' thinking.

- Presents challenges through the problem of project solving and monitors progress in product creation.

- Provides a variety of learning resources for student learning.

- Employs assessment methods that cover the evaluation of work pieces, work processes, and student competencies in addition to students' learning achievement.

- Summarizes and encourages students to discuss and realize the value and the correct approach to take after the activity.

2.1.1.2) The characteristics of the students are as follows.

- Responsible for learning and a desire to learn by themselves rather than people waiting to learn according to the teacher's instruction.

- Dare to express opinions and present and share knowledge and expertise with others.

- Work as a group to learn together and know how to determine their duties, including roles of group members.
- Search for resources to solve real world problems in the context of everyday life.

- Possess self-learning skills and can search for knowledge from various learning resources.

- Can create work pieces through self-learning of the content.

- Can evaluate their learning.

- Lecturer and experts should be knowledgeable and have expertise in various fields that teachers and students need to rely on, such as virtual technology, contents and interactive media, contents for teaching and learning, and so on.

- Evaluators should be knowledgeable and expert in technical aspects of virtual technology and content used as teaching materials.

- The system administrators are responsible for overseeing various systems that will support the development of interactive learning media with augmented reality using the Imagineering Process for the SMART Classroom and enable the teaching and learning process to proceed smoothly and efficiently.

\subsection{2) Software}

2.1.2.1) The characteristics of the software of the augmented reality development tool are as follows.

- Must be flexible and interact with users, which denotes the relationship between the real environment and the virtual environment.

- Must be able to increase learning efficiency, help students understand using less time to learn, and reduce the intellectual burden, resulting in effective learning.

- Must help to transform abstract content into concrete.

- Must be convenient to use and facilitate learning without the need for large-scale experimental equipment or a large amount of materials, thus reducing the cost of purchasing equipment. This allows students to learn by themselves with a variety of devices.

- Must motivate students to learn and promote independent learning.

- Is a multimedia medium that allows students to learn by themselves according to their potential and needs.

- Helps students to transform abstract experiences into concrete ones, stimulating their interest and enhancing a positive attitude towards learning.

- Must enhance cooperative learning, resulting in collaboration between students and teachers in which students interact well between groups. This enhances the creation of realistic pieces in different contexts. 
2.1.2.2) Learning Management System (LMS) provides features to support the teaching and learning process via the Internet, such as access to courses, lessons, and exercises.

2.1.2.3) Database Management System (DBMS) provides features for storing the information of teachers, learners, and course results.

\subsection{3) Hardware}

The hardware consists of a 3D projector or 3D visualizer, smart board, automatic detection as camera auto tracking, distribution system as a streaming system, and an internet access point.

\subsection{4) Procedure}

The procedure used to develop interactive learning materials with augmented reality is based on the Imagineering process model which consists of the following 6 steps:

2.1.4.1) Imagination motivation consists of the determination of the problem and brainstorming, expressing ideas or discussion, analysing the possibilities of imagination or feasibility. This step helps motivate students, making them interested in learning and creating inspiration.

2.1.4.2) Designing cooperation is a draft process that consists of storyboard writing, scripting, and prototype designing. This step facilitates participation in learning and creates interaction between students and teachers.
2.1.4.3) Developing practice is the process of creating and testing work. This step is one of practice and innovation as it involves using learning materials from technology that students have practiced in the form of projects, work pieces, or innovations.

2.1.4.4) Presenting creation is the process of showing work, engaging in contests, and eliciting comments and suggestions. This step helps promote creativity and participation.

2.1.4.5) Improving feedback is the process of revising and concluding the work. This step improves the work from the presentation, which encourages students to reflect on the ideas that they have learned and express their opinions reasonably.

2.1.4.6) Evaluating authentication is an evaluation process based on imagination and product evaluation according to the actual situation regarding the workpiece and the learner. This step involves assessing learners' understanding of the learning process by evaluating both friends and teachers.

\subsection{5) Data and information}

Data and information is part of the development of interactive learning materials with augmented reality and consists of learning resources, a knowledge and learning media repository, and important contents.

\section{2) The interactive learning media} development model with augmented reality using the Imagineering process for the SMART classroom.

The results indicate the model includes 4 processes: preparation, master teacher development, magnify an outcome, and evaluation, as indicated in Figure 5.
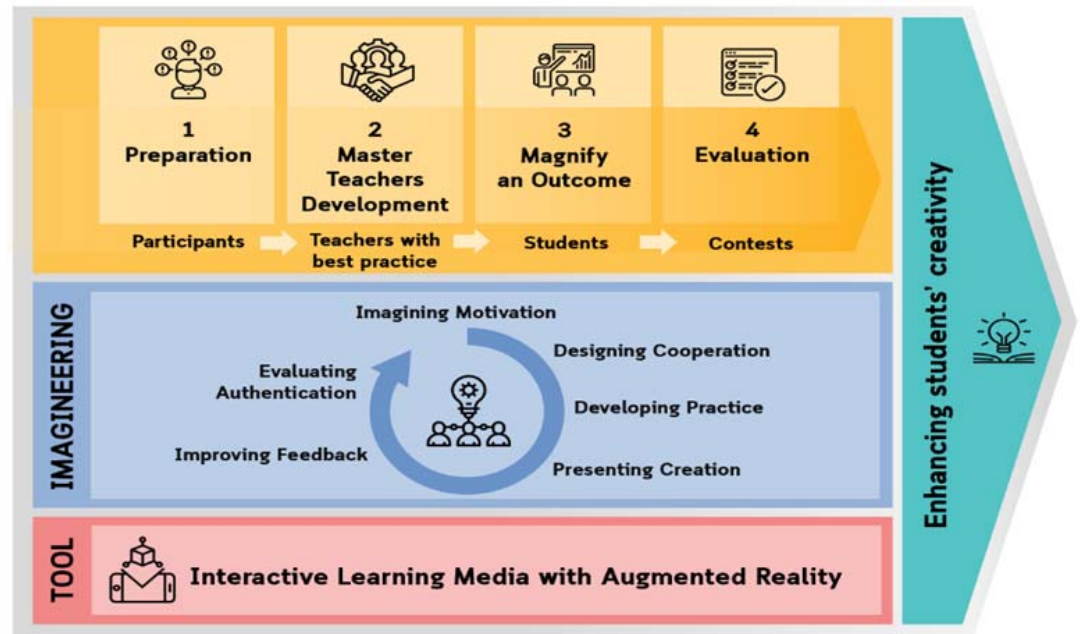

Figure 5. The Interactive Learning Media Development Model with Augmented Reality using the Imagineering Process for the SMART Classroom 
The sub-processes of the interactive learning media development model are as follows.

\section{Preparation}

This involves preparing for the interactive learning media development model, based on the human performance technology (HPT Model) model presented in Figure 6.

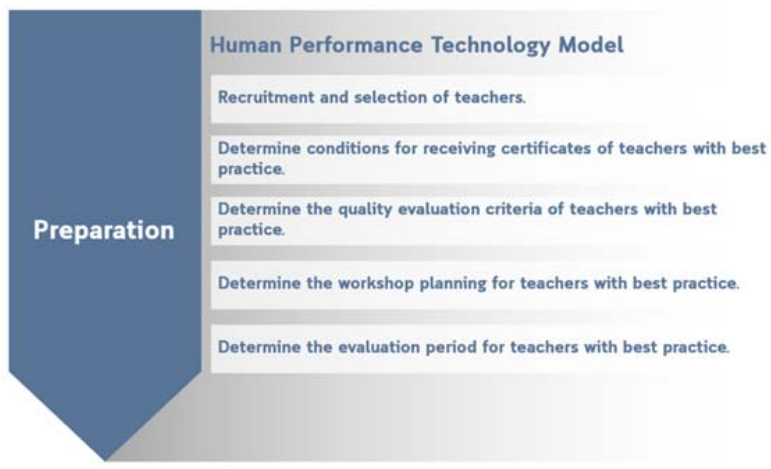

Figure 6. Preparation stage

As indicated, preparation consists of the following activities:

- Recruitment and selection of 50 teachers under the Ministry of Education.

- Determine the conditions for receiving certificates of teachers with best practice.

- Determine the quality evaluation criteria for teachers with best practice that indicates such teachers must be able to develop augmented reality for the SMART classroom.

- Determine workshop planning for teachers with best practice for 5 days.

- Determine the evaluation period for teachers with best practice after the workshop has finished.

\section{Master teacher development}

Master teacher development for the interactive learning media development model occurs as shown in Figure 7.

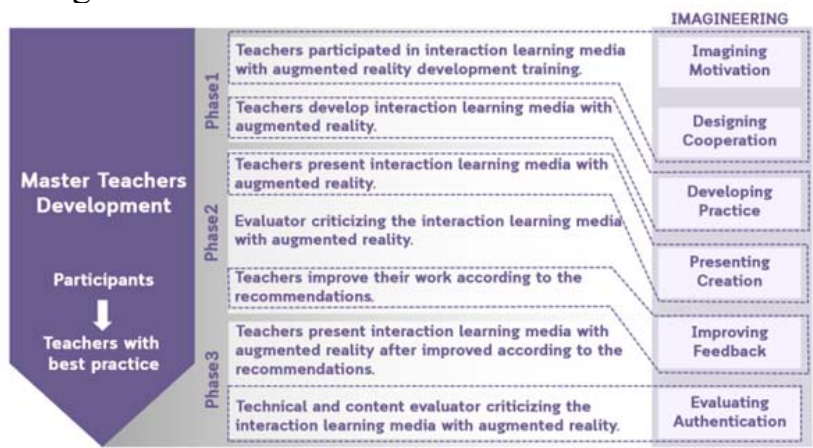

Figure 7. Master teacher development stage
As indicated in Figure 7., master teacher development consists of the following activities:

- Teachers participate in interaction learning media with augmented reality development training.

- 50 teachers develop interaction learning media with augmented reality to produce 50 projects.

- Teachers present their interaction learning media with augmented reality project.

- Evaluators critique the interaction learning media with augmented reality projects.

- Teachers improve their work according to the recommendations.

- Teachers present interaction learning media with augmented reality after making their improvements.

- Technical and content evaluator assess the interaction learning media with augmented reality.

- Report on the evaluation of master teacher development for the interactive learning media development model with augmented reality using the Imagineering process for the SMART classroom.

\section{Magnify an outcome}

Magnify an outcome is the stage after master teacher development for the interactive learning media development model with augmented reality, as depicted in Figure 8.

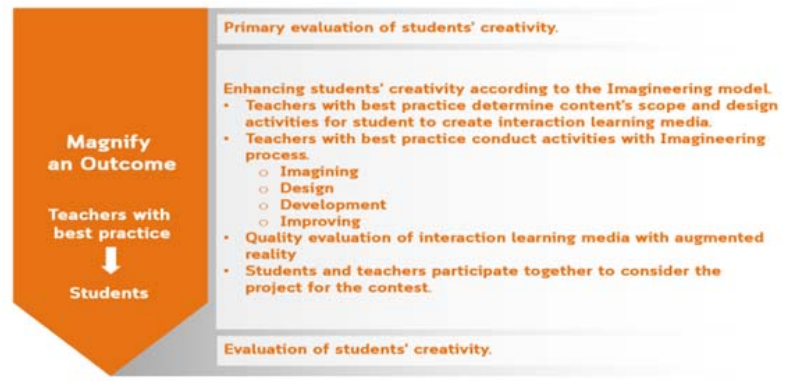

Figure 8. Magnify an outcome stage

As indicated, magnify an outcome consists of the following activities:

- Primary evaluation of students' creativity before participating in the workshop.

- Enhancing students' creativity according to the Imagineering model. Teachers with best practices determine the scope of contents and design activities for students to create interactive learning media. Teachers with best practice conduct activities using the Imagineering process, which consists of imagining, design, development, and improving.

- Quality evaluation of interaction learning media with augmented reality.

- Students and teachers work together to consider the project for the contest.

- Evaluation of students' creativity. 


\section{Evaluation}

Evaluation of the interactive learning media development model with augmented reality using the Imagineering process for SMART classroom is presented in Figure 9.

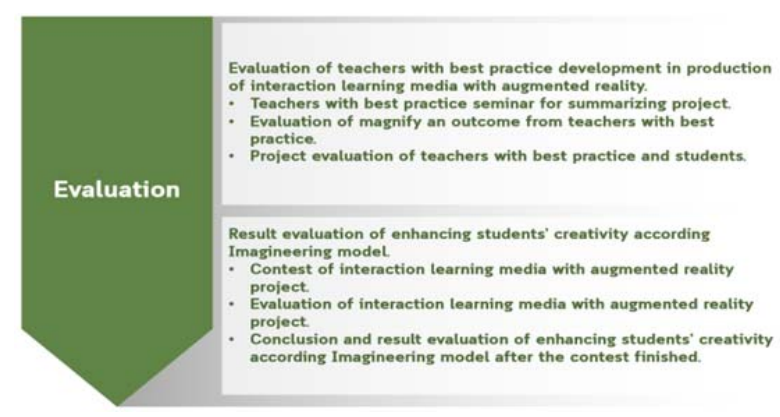

Figure 9. Evaluation stage

As indicated, the evaluation process consists of the following activities:

- Evaluation of the development of teachers with best practices in the production of interaction learning media with augmented reality.

- Teachers with best practice conduct a seminar to summarize the project.

- Evaluation of magnifying an outcome from teachers with best practices.

- Project evaluation of teachers with best practices and students.

- Result of enhancing students' creativity according to the Imagineering model.

- Contest involving the interaction learning media with augmented reality project.

- Evaluation of interaction learning media with augmented reality project.

- Conclusion and evaluation of the enhancement of students' creativity according to the Imagineering model after the contest has finished.

2.3) The results of developing teachers with best practice in the production of interactive learning media with augmented reality using the Imagineering process for the SMART classroom.

50 teachers with best practices trained, using the interactive learning media development model were able to develop interactive learning media of extremely good quality.

\section{4) The results of magnify an outcome for} students.

1,500 students in higher education and vocational education trained, using the Imagineering process exhibited creativity at a high level and the quality evaluation results for creativity innovation were at the highest level.

Part 3: Results for the Ministry of Education's best practice teachers of information and communication technology regarding the production of learning materials with the augmented reality interactive learning model using the Imagineering process for the SMART classroom.

3.1) The results for those teachers who participated in the workshop are presented in Table 1-2.

Table 1. Results for the Ministry of Education's best practice teachers in information and communication technology regarding the production of learning materials with the augmented reality interactive learning model using the Imagineering process for the SMART classroom $(n=50)$.

\begin{tabular}{|c|c|c|c|}
\hline Assessment list & $\bar{X}$ & S.D. & Opinions \\
\hline $\begin{array}{l}\text { 1. The Knowledge and } \\
\text { Understanding gained on } \\
\text { Imagineering Learning } \\
\text { Management. }\end{array}$ & 4.74 & 0.49 & Excellent \\
\hline $\begin{array}{l}\text { 2. The Knowledge and } \\
\text { Understanding gained in } \\
\text { Imagineering Learning for } \\
\text { Augmented Reality } \\
\text { interactive learning } \\
\text { management. }\end{array}$ & 4.61 & 0.71 & Excellent \\
\hline $\begin{array}{l}\text { 3. The Knowledge and } \\
\text { Understanding gained in the } \\
\text { development of Learning } \\
\text { materials with the } \\
\text { Augmented Reality } \\
\text { interactive model. }\end{array}$ & 4.67 & 0.63 & Excellent \\
\hline $\begin{array}{c}\text { Total } \\
\end{array}$ & 4.67 & 0.62 & Excellent \\
\hline
\end{tabular}

As indicated in Table 1., the best practice teachers exhibited an excellent level of knowledge and understanding as a result of participating in the overall program $(\bar{X}=4.67$, S.D. $=0.62)$. When considered individually, the knowledge and understanding gained in relation to Imagineering learning management was at the Excellent level knowledge and understanding gained on the development of learning materials with the Augmented Reality interactive model $(\bar{X}=4.67$, SD $=0.63$ ) and the knowledge and understanding gained on Imagineering Learning Management ( $\bar{X}=4.61$, $\mathrm{SD}=0.71)$, respectively. 
Table 2. The ability of the Ministry of Education's best practice teachers of information and communication technology regarding the production of learning materials with the Augmented Reality interactive learning model using the Imagineering Process for the SMART classroom $(n=50)$

\begin{tabular}{|c|c|c|c|}
\hline Assessment list & $\bar{X}$ & S.D. & Opinions \\
\hline $\begin{array}{l}\text { 1. Able to organize learning } \\
\text { activities with Imagineering } \\
\text { to develop innovation for } \\
\text { learners. }\end{array}$ & 4.76 & 0.43 & Excellent \\
\hline $\begin{array}{l}\text { 2. Able to produce interactive } \\
\text { learning materials with } \\
\text { Augmented Reality using the } \\
\text { Imagineering Process. }\end{array}$ & 4.76 & 0.48 & Excellent \\
\hline $\begin{array}{l}\text { 3. Able to apply the } \\
\text { knowledge gained to } \\
\text { introduce others to the } \\
\text { material. }\end{array}$ & 4.67 & 0.52 & Excellent \\
\hline $\begin{array}{l}\text { 4. Able to apply the acquired } \\
\text { knowledge to further extend } \\
\text { the results with students }\end{array}$ & 4.76 & 0.48 & Excellent \\
\hline $\begin{array}{l}\text { 5. Exhibit the ability to } \\
\text { become an Imagineering } \\
\text { Instructional Designer. }\end{array}$ & 4.91 & 0.35 & Excellent \\
\hline $\begin{array}{c}\text { Total } \\
\end{array}$ & 4.77 & 0.46 & Excellent \\
\hline
\end{tabular}

As indicated in Table 2., the ability of teachers with overall excellent practice to apply knowledge was at the Excellent level $(\bar{X}=4.77, \mathrm{SD}=0.46)$. When considered individually, the ability to become an Imagineering Instructional Designer was at the Excellent level $(\bar{X}=4.91, \mathrm{SD}=0.35)$, followed by the ability to organize learning activities in Imagineering for the innovative development of learners $(\bar{X}=4.76$, S.D. $=0.43)$, and the ability to produce interactive learning materials with Augmented Reality using the Imagineering Process and further extend the knowledge obtained to the students $(\bar{X}=4.76$, S.D. $=0.48)$, respectively.

3.2) Excellent practice teachers were found to obtain interactive learning materials with Augmented Reality using the Imagineering Process for the SMART classroom. There were 36 works for the tertiary level and 37 works for vocational education.

The interactive learning materials developed by teachers demonstrated good overall technical quality and excellent content.

\section{Part 4: Expansion of the augmented reality interactive learning material using the Imagineering process for the SMART classroom.}

The results for the expansion of the augmented reality interactive learning material using the Imagineering process for the SMART classroom were as follows.

4.1) 30 tertiary prototype teachers received 311 works of interactive learning materials while 20 vocational prototype teachers received 200 works of interactive learning materials, a total of 511 works.

4.2) Teachers were able to organize learning activities for learners based on the Imagineering process at a ratio of 1:50 people. According to the project objectives and the interactive learning materials developed by the learners, both the overall technical quality and the overall content were good.

4.3) The 1,5000 tertiary and vocational students who used the Imagineering process exhibited a high level of creativity and the quality of creative innovation was at the highest level.

\section{Discussion}

The objective of this research is to create an augmented reality interactive learning model using the Imagineering process for the SMART classroom. The results indicate that:

The Augmented reality interactive learning model using the Imagineering process for the SMART classroom consists of (1) teachers, students, the SMART classroom environment, learning resources, Augmented Reality, and contents. (2) Interactive learning activities consist of the motivating imagination stage, the participatory design stage, the practical development stage, the creative presentation stage, the thoughtful improvement stage, and the real evaluation stage. (3) The Augmented reality interactive learning environment consists of five dimensions: S: Showing, M: Manageable, A: Accessible, R: Real-time Interactive, and T: Testing. Qualified experts certified that the interactive learning model developed is at the most appropriate level. Such technology focused on interactive learning environment ignites excitement among the students towards the concept of innovation [22]. One important outcome of this work is a set of design principles for supporting smart classroom [23].

The development of augmented reality interactive learning materials using the Imagineering process for the SMART classroom consists of (1) learning materials, namely related personnel, software, hardware, processes, data, and information. (2) The interactive learning material activities consist of four main processes: preparation, prototype teacher development, outreach, and evaluation. 50 prototype teachers with excellent practice in information and communication technology were able to apply the acquired knowledge to further study, practice, and learners at the highest level. The teacher's position increases the learner's motivation, engagement and effective learning [24]. AR technology may have the potential to enhance students' learning outcomes at the analysing level and their learning attitudes.

The augmented reality interactive learning for prototype teachers had good technical quality overall, and the content was extremely good. AR as a tool for 
interactive learning in various fields of education, and its contribution towards student motivation in classroom scenarios [25]. It was found that the designed AR learning activities encouraged the participants to discuss the concepts with peers, enhanced their immersive experience [26]. Integrating interactive learning systems with traditional ones and harmoniously combining them may help improve the overall structure of the learning process and boost student progress [27].

The expansion of the augmented reality interactive learning material using the Imagineering process for the SMART classroom enabled prototype teachers to organize learning activities according to objectives and tertiary students. The vocational education of 1,5000 people students using Imagineering learning exhibited a high level of creativity. The results of the evaluation indicate that the quality of creative innovation was at the highest level, the study also found that augmented reality technology did not affect the course engagement of students [28]. In addition, there are statistically significant differences in terms of professional experience, so that younger teachers tend to implement methodologies based on the use of emerging mobile technologies, such as augmented reality [29].

\section{Conclusion}

The interactive learning media development model with augmented reality, using Imagineering process for SMART classroom, consisting of the elements of interactive learning media development model with augmented reality using Imagineering process for SMART classroom include 5 factors: peopleware, software, hardware, procedure, and data and information. The activities of interactive learning media development model with augmented reality use Imagineering process for SMART classroom. The results of this research correspond with virtual technology likely to become a standard component of education. In addition, this work discusses the features of augmented reality technology as a technology that helps teachers to explain abstract topics more effectively, which is consistent with the results of this research, that augmented reality technology enhances learning efficiency and allowing students to understand abstract content by using less learning time. From the research results, it was found that augmented reality technology and Imagineering process are flexible in teaching and learning. They can be adapted to various teaching methods and contexts that use augmented reality technology for learning in the SMART classroom as a learning source database and used to review knowledge as a teaching media for students to create work pieces.

\section{Acknowledgements}

The interactive learning media development model with augmented reality using Imagineering process for SMART classroom was achieved by supporting the budget from Office of the Secretary for Educational Technology Development Fund, Ministry of Education, Thailand. The title of the project is "Development of interactive learning media using augmented reality for smart classroom based on Imagineering model", the project code is 35/2560, the time period of the project from July 2017 to July 2018. The researcher would like to deeply grateful. Thank you Assoc.Prof.Dr.Pallop Piriyasurawong and Dr.Phibul Choompolpaisal for supplying support and suggestions that are extremely helpful in this research.

\section{References}

[1]. Abykanova, B., Nugumanova, S., Yelezhanova, S., Kabylkhamit, Z., \& Sabirova, Z. (2016). The Use of Interactive Learning Technology in Institutions of Higher Learning. International Journal of Environmental and Science Education,11(18), 12528-12539.

[2]. Aguilar, J., Cordero, J., \& Buendía, O. (2018). Specification of the autonomic cycles of learning analytic tasks for a smart classroom. Journal of Educational Computing Research, 56(6), 866-891.

[3]. Alkhatib, O. J. (2018). An interactive and blended learning model for engineering education. Journal of Computers in Education, 5(1), 19-48.

[4]. Revathi, R., Suganya, M., \& NR, G. M. (2020). IoT based Cloud Integrated Smart Classroom for smart and a sustainable Campus. Procedia Computer Science, 172, 77-81.

[5]. Bdiwi, R., de Runz, C., Faiz, S., \& Cherif, A. A. (2019). Smart Learning Environment: Teacher's Role in Assessing Classroom Attention. Research in Learning Technology, 27.

[6]. Boonkua, A., Tuntinakorngul, A., \& Tungkunanan, P. (2020). Innovative Organization's Components in Basic Education Institutions in Thailand. International Journal of Instruction, 13(3), 31-42.

[7]. Choolarb, T., Premsmith, J., \& Wannapiroon, P. (2019, October). Imagineering Gamification using Interactive Augmented Reality to develop Digital Literacy Skills. In Proceedings of the 2019 The 3rd International Conference on Digital Technology in Education (pp. 39-43).

[8]. Dole, S. F., Bloom, L. A., \& Doss, K. K. (2016). Rocket to Creativity: A Field Experience in ProblemBased and Project-Based Learning. Global Education Review, 3(4), 19-32.

[9]. Guntha, R., Hariharan, B., \& Rangan, P. V. (2020). Analysis of Multimedia Communication Issues in the Immersive Smart Classroom System-A Control Center Approach. Procedia Computer Science, 171, 2600-2609.

[10]. Ke, S., Xiang, F., Zhang, Z., \& Zuo, Y. (2019). A enhanced interaction framework based on VR, AR and MR in digital twin. Procedia Cirp, 83, 753-758. 
[11]. Kwet, M., \& Prinsloo, P. (2020). The 'smart'classroom: a new frontier in the age of the smart university. Teaching in Higher Education, 25(4), 510-526.

[12]. Li, H., Kim, M. K., \& Xiong, Y. (2020). Individual learning vs. interactive learning: A cognitive diagnostic analysis of MOOC students' learning behaviors. American Journal of Distance Education, 34(2), 121-136.

[13]. López Belmonte, J., Pozo Sánchez, S., Fuentes Cabrera, A., \& Romero Rodríguez, J. M. (2020). Uses and integration of augmented reality in the educational cooperatives of Andalusia (Spain). JOTSE: Journal of Technology and Science Education, 10(1), 4-16.

[14]. Marcel, F. (2019). Mobile augmented reality learning objects in higher education. Research in Learning Technology, 27.

[15]. Nilsook, P., Utakrit, N., \& Clayden, J. (2014). Imagineering in Education: A framework to enhance students' learning perfomance and creativity in thinking. Educational technology: The magazine for managers of change in education, 54(1), 14-20.

[16]. Office of the National Education Commission. (2014). National Education Act. Bangkok: Office of the Prime Minister, Thailand. Retrieved from: http://planipolis.iiep.unesco.org/upload/Thailand/Tha iland_Education_Act 1999.pdf [accessed: 10 January 2021].

[17]. Phoong, S. Y., Phoong, S. W., Moghavvemi, S., \& Sulaiman, A. (2019). Effect of smart classroom on student achievement at higher education. Journal of Educational Technology Systems, 48(2), 291-304.

[18]. Kaur, D. P., Mantri, A., \& Horan, B. (2020). Enhancing Student Motivation with use of Augmented Reality for Interactive Learning in Engineering Education. Procedia Computer Science, 172, 881-885.

[19]. Prosperi, L. J. (2016). The Imagineering pyramid: Using Disney theme park design principles to develop and promote your creative ideas. Theme Park Press.
[20]. Recalde, J. M., Palau, R., Galés, N. L., \& Gallon, R. (2020). Developments for Smart Classrooms: School Perspectives and Needs. International Journal of Mobile and Blended Learning (IJMBL), 12(4), 3450.

[21]. Rogers, S. L. (2020). Cheap, accessible, and virtual experiences as tools for immersive study: a proof of concept study. Research in Learning Technology, 28.

[22]. Steele, P., Burleigh, C., Bailey, L., \& Kroposki, M. (2020). Studio Thinking Framework in Higher Education: Exploring Options for Shaping Immersive Experiences Across Virtual Reality/Augmented Reality Curricula. Journal of Educational Technology Systems, 48(3), 416-439.

[23]. Steele, P., Burleigh, C., Kroposki, M., Magabo, M., \& Bailey, L. (2020). Ethical Considerations in Designing Virtual and Augmented Reality Products-Virtual and Augmented Reality Design With Students in Mind: Designers' Perceptions. Journal of Educational Technology Systems, 49(2), 219-238.

[24]. Sanglub, A., Nilsook, P., \& Wannapiroon, P. (2019). Imagineering on Augmented Reality and Digital Twin for Digital Competence. International Journal of Information and Education Technology, 9(3), 213217.

[25]. The office of the education council. (2016). National Education Plan 2017 -2036. Bangkok: Ministry of Education, Thailand.

[26]. Tissenbaum, M., \& Slotta, J. D. (2019). Developing a smart classroom infrastructure to support real-time student collaboration and inquiry: a 4-year design study. Instructional Science, 47(4), 423-462.

[27]. Vasilevski, N., \& Birt, J. R. (2020). Analysing construction student experiences of mobile mixed reality enhanced learning in virtual and augmented reality environments. Research in Learning Technology, 28, 1-23.

[28]. Weng, C., Otanga, S., Christianto, S. M., \& Chu, R. J. C. (2020). Enhancing students' biology learning by using augmented reality as a learning supplement. Journal of Educational Computing Research, 58(4), 747-770.

[29]. Yeh, H. C., \& Tseng, S. S. (2019). Using the ADDIE model to nurture the development of teachers' CALL professional knowledge. Journal of Educational Technology \& Society, 22(3), 88-100. 